\title{
Sustainability of thorium-uranium in pebble-bed fluoride salt-cooled high temperature reactor
}

\author{
Guifeng Zhu ${ }^{1,3}$, Yang Zou ${ }^{1,2}$, and Hongjie $\mathrm{Xu}^{1,2^{*}}$ \\ ${ }^{1}$ Shanghai Institute of Applied Physics, Chinese Academy of Sciences, Jialuo Road 2019\#, Jiading District, 201800 Shanghai, \\ P.R. China \\ ${ }^{2}$ Key Laboratory of Nuclear Radiation and Nuclear Energy Technology, Chinese Academy of Sciences, Jialuo Road 2019\#, \\ Jiading District, Shanghai, P.R. China \\ ${ }^{3}$ University of Chinese Academy of Sciences, No. 19A Yuquan Road, Beijing, P.R. China
}

Received: 11 May 2015 / Received in final form: 25 October 2015 / Accepted: 18 December 2015

Published online: 7 March 2016

\begin{abstract}
Sustainability of thorium fuel in a Pebble-Bed Fluoride salt-cooled High temperature Reactor (PBFHR) is investigated to find the feasible region of high discharge burnup and negative Flibe $\left(2 \mathrm{LiF}-\mathrm{BeF}_{2}\right)$ salt Temperature Reactivity Coefficient (TRC). Dispersion fuel or pellet fuel with SiC cladding and $\mathrm{SiC}$ matrix is used to replace the tristructural-isotropic (TRISO) coated particle system for increasing fuel loading and decreasing excessive moderation. To analyze the neutronic characteristics, an equilibrium calculation method of thorium fuel self-sustainability is developed. We have compared two refueling schemes (mixing flow pattern and directional flow pattern) and two kinds of reflector materials ( $\mathrm{SiC}$ and graphite). This method found that the feasible region of breeding and negative Flibe TRC is between $20 \mathrm{vol} \%$ and $62 \mathrm{vol} \%$ fuel loading in the fuel. A discharge burnup could be achieved up to about $200 \mathrm{MWd} / \mathrm{kgHM}$. The case with directional flow pattern and $\mathrm{SiC}$ reflector showed superior burnup characteristics but the worst radial power peak factor, while the case with mixing flow pattern and $\mathrm{SiC}$ reflector, which was the best tradeoff between discharge burnup and radial power peak factor, could provide burnup of $140 \mathrm{MWd} / \mathrm{kgHM}$ and about $1.4 \mathrm{radial}$ power peak factor with $50 \mathrm{vol} \%$ dispersion fuel. In addition, Flibe salt displays good neutron properties as a coolant of quasi-fast reactors due to the strong ${ }^{9} \mathrm{Be}(\mathrm{n}, 2 \mathrm{n})$ reaction and low neutron absorption of ${ }^{6} \mathrm{Li}$ (even at $1000 \mathrm{ppm}$ ) in fast spectrum. Preliminary thermal hydraulic calculation shows good safety margin. The greatest challenge of this reactor may be the decades irradiation time of the pebble fuel.
\end{abstract}

\section{Introduction}

The sustainability of nuclear energy resources has aroused great interest and attention since the Generation IV International Forum. A reactor system with breeding capability is very essential to extend the sustainability of nuclear fuel resources. Liquid metal-cooled fast reactor is the preferred choice to achieve a high breeding ratio. However, it has some obstacles due to safety concerns associated with a positive void reactivity.

Thorium seems an attractive option of nuclear resources mainly due to its abundance, the opportunity to reduce the need for enrichment in the fuel cycle, the high conversion ratios (to ${ }^{233} \mathrm{U}$ ) achievable in a thermal neutron spectrum, and also due to other neutron and thermal physical properties studied early in the development of nuclear power [1]. Due to the high effective number of neutrons for

\footnotetext{
* e-mail: xuhongjie@sinap.ac.cn
}

each ${ }^{233} \mathrm{U}$ fission in a thermal and epithermal neutron spectrum, thorium breeding is feasible in most existing and prospective reactor designs (including LWRs [2,3], HWRs [4-8], HTGRs [9] and molten salt reactors [10-12]), and it can provide the negative void reactivity coefficient due to the softer neutron spectrum than that of fast reactor. However, the thorium breeding gain in these reactors is far lower than fast reactor's. From an economical view, it is better to maintain fissile self-sustainability and to improve burnup for decreasing reprocessing mass per electricity.

This work focuses on sustainability of thorium in a Pebble-Bed Fluoride salt-cooled High temperature Reactor [13-16] (PB-FHR), to find its feasible region of high burnup and negative void reactivity coefficient. Expectant advantages of Flibe salt $\left(2 \mathrm{LiF}-\mathrm{BeF}_{2}\right)$ as breeder reactor coolant [17] are that heat-carrying capacity and boiling point are both high; weak neutron slowing-down power will allow more coolant volume ratio than HWRs; and it may provide more negative temperature reactivity coefficient due to strong $(n, 2 n)$ reaction of ${ }^{9} \mathrm{Be}$ in the fast spectrum. 
Furthermore, PB-FHR is neutron saving with refueling online, and ${ }^{233} \mathrm{~Pa}$ has the chance to decay away when thorium fuel is periodically removed from the core. However, one disadvantage is that Flibe salt in a flowing pebble bed will occupy about $40 \%$ volume of core, which enhances the moderation of Flibe and decreases the fuel inventory, as a result, a critical design should be required in fuel system of breeder PB-FHR.

The system of tristructural-isotropic (TRISO) coated fuel particles embedded in massive graphite matrix in thermal spectrum PB-FHRs is not adaptable to breeder reactor concepts due to its low fissile loading, the high irradiation swelling behavior of graphite in a quasi-fast spectrum, and the excessive moderation due to the large graphite/fuel ratio. Two kinds of fuel system [18] are developed for gas-cooled fast reactor (GFR) in order to increase fuel loading and improve radiation resistivity, which could be applied to PB-FHRs. One is pin-type GFR fuel with refractory cladding material (Fig. 1a); another one is dispersion fuel (or composite fuel or sphere-pac fuel) consisting of a distribution of discrete fuel particles embedded in a non-fuel matrix (Fig. 1b). Usually, fuel loading in dispersion fuel can reach $50 \mathrm{vol} \%$, and in pin-type fuel is beyond $75 \mathrm{vol} \%$ [19]. Buffer layers are both designed in pin-type fuel and dispersion fuel to provide volume for
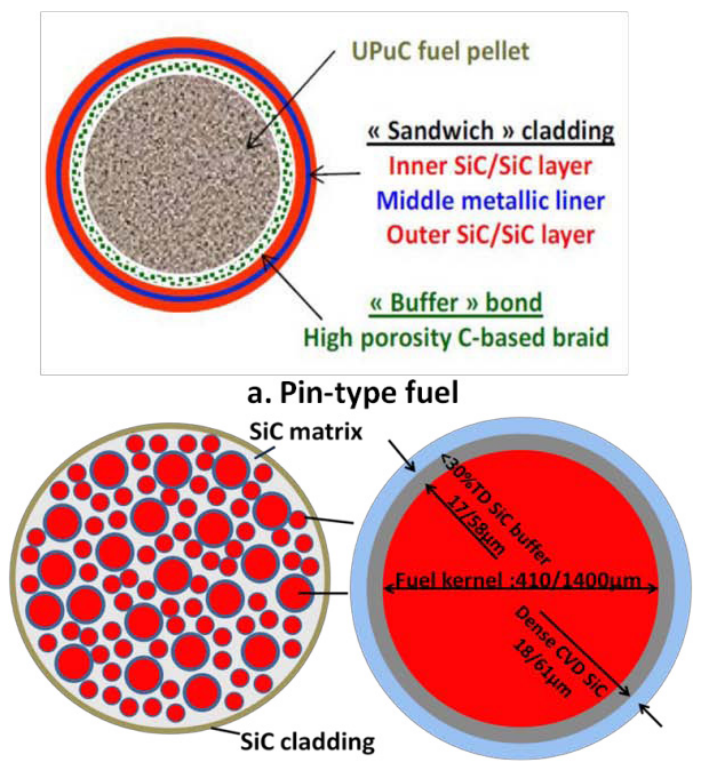

b. Dispersion fuel

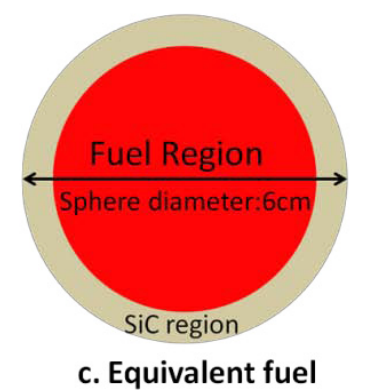

Fig. 1. Fuel system: a. pin-type fuel with $\mathrm{SiC} / \mathrm{SiC}$ cladding; b. dispersion fuel filled with two kinds of coated fuel particle; c. equivalent fuel used for neutron calculation in this work. fission gas and provide volume for fuel particle swelling. $\mathrm{SiC}$ is a good candidate cladding material or matrix material because of the good irradiation swelling behavior of $\mathrm{SiC}$ [20-25], the large irradiation behavior database, and the experience in use of $\mathrm{SiC}$ as a component in TRISO fuel. In addition, $\mathrm{SiC}$ has excellent oxidation resistance due to rapid formation of a dense, adherent $\mathrm{SiO}_{2}$ surface scale on exposure to air at elevated temperature, which offers protection from further oxidation. $\mathrm{SiC}$ is effective for retention of the solid fission products [26], but the migration of $\mathrm{Ag}$ in polycrystalline $\mathrm{SiC}$ can occur. Middle metallic liner designed in pin-type fuel and $\mathrm{SiC}$ matrix in dispersion fuel ensure such fission product confinement within the fuel system.

For a preliminary concept design, the fuel system of thorium fuel self-sustainability in PB-FHRs is considered as dispersed fuel particle filled in a sphere cladding. In order to simplify neutron calculation, an equivalent fuel system with only thorium fuel region and $\mathrm{SiC}$ region (Fig. 1c) is used because the weak moderation of $\mathrm{SiC}$ makes the space selfshielding effect insignificant. Oxy-carbide thorium fuel is chosen in this work due to stable fission products bound by oxygen, low internal pressure for low product of free oxygen and compatibility with $\mathrm{SiC}$ material.

In order to simplify refueling scheme, homogeneous system with one kind of ${ }^{233} \mathrm{U} /{ }^{232} \mathrm{Th}$ pebble is carried out, in which mixing flow pattern and directional flow pattern are both performed. For neutronic analysis of thorium fuel selfsustainability, neutron spectrum is adjusted by fuel loading variable $V_{f}$, which is defined as fuel volume dividing the volume of fuel system. In addition, graphite reflector is compared with $\mathrm{SiC}$ reflector to evaluate the moderation effect of reflector. Reactor model and refueling scheme are introduced in Section 2. Equilibrium calculation method of fissile self-sustainability is represented in Section 2.2. In Section 3, we show the results and discussions, in which achievable burnup of thorium fuel self-sustainability, temperature reactivity coefficient of Flibe, radial power distribution and preliminary thermal hydraulics are analyzed. Conclusions are drawn in Section 4.

\section{Model and calculation method}

\subsection{Reactor model and refueling scheme}

Reactor model is simplified to a cylinder (Fig. 2). The core is divided into five radial annular flow channels with the same cross-sectional area. Each channel is uniformly segmented into seven axial layers. In all, 35 burnup regions are used for neutronic calculation. Graphite or $\mathrm{SiC}$ is chosen as the material of both the axial and the radial reflector. Vacuum boundary condition is assumed outside the reflector. The layout of control rods and the $\mathrm{B}_{4} \mathrm{C}$ shielding layer are outside the scope of this article, and are omitted in the equilibrium calculation. Dimensions of reactor are shown in Table 1. The diameter of pebble is chosen as $6 \mathrm{~cm}$, but it may be changed for thermal hydraulic considerations. ${ }^{233} \mathrm{U} /{ }^{232} \mathrm{Th}$ pebbles are loaded in the core with a volumetric filling fraction of 0.6 . 


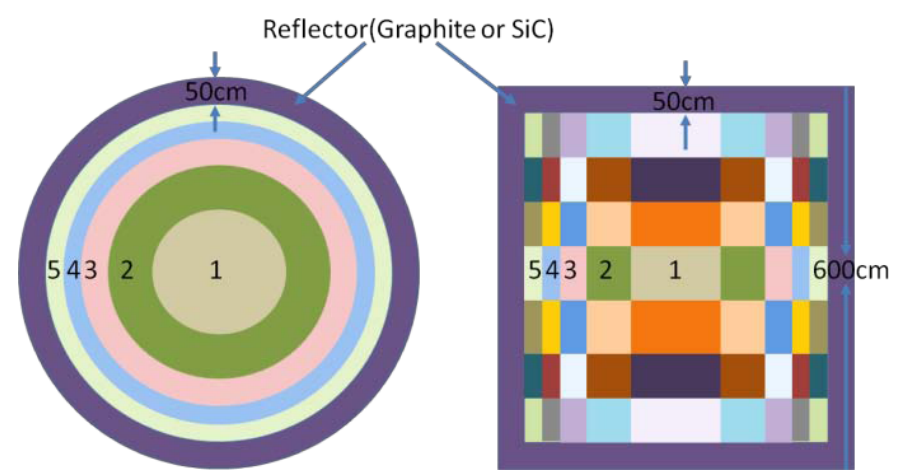

Fig. 2. Schematic view of the reactor geometry used during the neutronics calculation. On the left is the vertical view of the middle layer of the right horizontal view. Arabic numbers represent radial channels.

$V f$ in pebble is varied by changing the packing factor. Usually, packing factor for the binary size particles is higher than unary size particle, in this paper, the packing factor in pin filling model is 0.73 calculated by equation from literature [27] (in sphere filling model, it will be lower than 0.73 ), fuel loading in particle could reach $78 \%$, thus, the limiting $V f$ is $0.73 \times 0.78=0.57$. However, for neutronic analysis, $V f$ beyond 0.57 is also performed. Material properties of reactor are listed in Table $2 .{ }^{6} \mathrm{Li}$ in Flibe salt is assumed to be $22 \mathrm{ppm}$ referred to literature [28], while the equilibrium concentration of ${ }^{6} \mathrm{Li}$ will be analyzed in the following section. Fresh ${ }^{233} \mathrm{U} /{ }^{232} \mathrm{Th}$ ratio $(U T R)$ is automatically adjusted in the equilibrium calculation for fissile self-sustainability.

Multiple-passage-through-the-core (ten passage chosen in this work) with two kinds of flow patterns is simulated to flatten the axial power distribution. The mixing flow pattern is defined as that where pebbles, unloaded from each channel and not reached the limit of discharge burnup, are mixed with a batch of fresh pebbles and then are randomly recycled into five channels. The directional flow pattern is defined as that where a batch of fresh pebbles is

Table 1. Dimensions of reactor.

\begin{tabular}{ll}
\hline Parameter & Dimension $(\mathrm{cm})$ \\
\hline Outer radius of Channel 1 & 107.33 \\
Outer radius of Channel 2 & 151.79 \\
Outer radius of Channel 3 & 185.9 \\
Outer radius of Channel 4 & 214.66 \\
Outer radius of Channel 5 & 240 \\
Height of active core & 500 \\
Thickness of axial and radial reflector & 50 \\
Diameter of equivalent fuel pebble & 6 \\
Kernel diameters of fuel particle & $0.0410 / 0.1400$ \\
Buffer thicknesses of fuel particle & $0.0017 / 0.0058$ \\
SiC thicknesses of fuel particle & $0.0018 / 0.0061$ \\
\hline
\end{tabular}

Table 2. Material properties of reactor.

\begin{tabular}{lrl}
\hline Material & Temperature $(\mathrm{K})$ & $\begin{array}{l}\text { Density } \\
\left(\mathrm{g} / \mathrm{cm}^{3}\right)\end{array}$ \\
\hline $\mathrm{Th}_{2} \mathrm{CO}_{3}{ }^{233} \mathrm{U}_{2} \mathrm{CO}_{3}$ & 1050 & 9.86 \\
$\mathrm{SiC}$ Matrix and cladding & 1000 & 3.2 \\
Flibe salt & 920 & 1.96 \\
Reflector (Graphite/SiC) & 880 & $1.74 / 3.2$ \\
\hline
\end{tabular}

Table 3. Core cases.

\begin{tabular}{ll}
\hline Case 1 & Mixing Flow, Graphite Reflector \\
Case 2 & Directional Flow, Graphite Reflector \\
Case 3 & Mixing Flow, SiC Reflector \\
Case 4 & Directional Flow, SiC Reflector \\
\hline
\end{tabular}

recycled 10 times in channel 1 , and then 10 times in channel 2 , and so forth until discharged from channel 5 . It is noteworthy that the radial position of pebbles in the core is determined by their inlet position [29], which implies that the directional flow could be easily achieved by only setting four baffles in the inlet. The out-pile residence time of pebble is supposed to be equal to in-pile residence time.

For the reprocessing of discharge fuel, only ${ }^{233} \mathrm{U}$ and ${ }^{232} \mathrm{Th}$ are extracted, while other uranium isotopes such as ${ }^{234} \mathrm{U},{ }^{235} \mathrm{U},{ }^{236} \mathrm{U}$, are omitted in the calculation due to the long equilibrium cycle. ${ }^{233} \mathrm{~Pa}$ from discharge fuel is regarded as ${ }^{233} \mathrm{U}$, and will be returned to core. In the general model, average power density is $10 \mathrm{MW} / \mathrm{m}^{3}$ (corresponding to $980 \mathrm{MW}$ total power), which will be changed in the analysis of ${ }^{233} \mathrm{~Pa}$ effect. According to the refueling scheme and reflector material, 4 cases are analyzed, as shown in Table 3.

\subsection{Equilibrium calculation method of thorium fuel self-sustainability}

Equilibrium calculation of thorium fuel self-sustainability involves searching the fuel feed rate (or in-pile residence time) and UTR to keep $k_{\text {eff }}$ convergent to 1 and to keep the ${ }^{233} \mathrm{U}$ fed into the core equivalent to ${ }^{233} \mathrm{U}$ from discharge fuel under different energy spectra. Convergence methods are analyzed below.

Ignoring the chain of ${ }^{233} \mathrm{~Pa}$ and ${ }^{233} \mathrm{Th}$, the evolution equations of ${ }^{232} \mathrm{Th}$ and ${ }^{233} \mathrm{U}$ can be shown as:

$$
\frac{d N_{T h}}{d t}=-A_{T h} N_{T h}
$$

$$
\frac{d N_{U 3}}{d t}=-A_{U 3} N_{U 3}+A_{T h} N_{T h} .
$$

$N_{T h}$ is the concentration of ${ }^{232} \mathrm{Th}$, and $A_{T h}$ is a function of fluxes and one-group capture cross-sections of ${ }^{232} \mathrm{Th}$ in 
different regions. $N_{U 3}$ is the concentration of ${ }^{233} \mathrm{U}$, and $A_{U 3}$ is a function as fluxes and one-group absorption crosssections of ${ }^{233} \mathrm{U}$ in different regions. After in-pile residence time $T$, the concentration of ${ }^{233} \mathrm{U}$ can be solved as follows:

$$
\begin{aligned}
N_{U 3}(T)= & \left(N_{U 30}-\frac{\bar{A}_{T h} \cdot N_{T h 0}}{\bar{A}_{U 3}-\bar{A}_{T h}}\right) \exp \left(-\bar{A}_{U 3} T\right) \\
& +\frac{\bar{A}_{T h} \cdot N_{T h 0}}{\bar{A}_{U 3}-\bar{A}_{T h}} \exp \left(-\bar{A}_{T h} T\right) .
\end{aligned}
$$

$N_{U 30}$ is the fresh concentration of ${ }^{233} \mathrm{U}$, and $N_{T h 0}$ is the fresh concentration of ${ }^{232}$ Th. $\bar{A}$ is time-averaged $A$. For fissile self-sustainability, $N_{U 3}(T)=N_{U 30}$. It can be deduced that:

$$
\begin{aligned}
U T R= & \frac{N_{U 30}}{N_{T h 0}}=\frac{\bar{A}_{T h}}{\bar{A}_{U 3}-\bar{A}_{T h}}\left(\exp \left(-\bar{A}_{T h} T\right)\right. \\
& \left.-\exp \left(-\bar{A}_{U 3} T\right)\right) /\left(1-\exp \left(-\bar{A}_{U 3} T\right)\right) .
\end{aligned}
$$

UTR always can be determined by in-pile residence time under specific $A$ which is affected by neutron energy spectrum and can be adjusted by $V f$.

In addition, for simplified analysis, an equation can be established to connect $k_{\text {eff }}$ with $T$ for fissile selfsustainability.

$$
k_{e f f}=\frac{1}{2 / \eta+L+A b s_{f p} \cdot T},
$$

$\eta$ is the effective number of ${ }^{233} \mathrm{U}$ fission neutrons, usually about 2.25 in epithermal spectrum. $L$ is the sum of neutron absorption rate of structure material and leakage rate of core. $A b s_{f p}$ is the equivalent capture absorption rate of fission products and transuranic elements. For the differential equation (5),

$$
\begin{aligned}
\frac{d k_{e f f}}{k_{e f f}} & =\frac{-A b s_{f p} \cdot T}{2+L+A b s_{f p} \cdot T} \frac{d T}{T} \\
& =\frac{A b s_{f p} \cdot T}{2+L+A b s_{f p} \cdot T} \frac{d V}{V}\left(\text { for } \frac{d T}{T}=-\frac{d V}{V}\right) .
\end{aligned}
$$

$V$ is feed rate of fresh fuel. Equation (6) can be changed into:

$$
\frac{d V}{V}=\left(1+\frac{2+L}{A b s_{f p} \cdot T}\right) \frac{d k_{e f f}}{k_{e f f}} .
$$

Supposing $L$ is equal to $2 \%$, and $k_{e f f}$ is $1, A b s_{f p} \cdot T$ can be obtained from equation (5). Equation (7) is changed into:

$$
\frac{d V}{V} \approx 10 \frac{d k_{e f f}}{k_{e f f}}
$$

Equation (8) describes a positive correlation between feed rate of fresh fuel and $k_{\text {eff }}$, and is used to modify feed rate of fresh fuel with previous $k_{\text {eff. }}$. Constant 10 in equation (8) does not affect the accuracy but determines the rate of convergence.

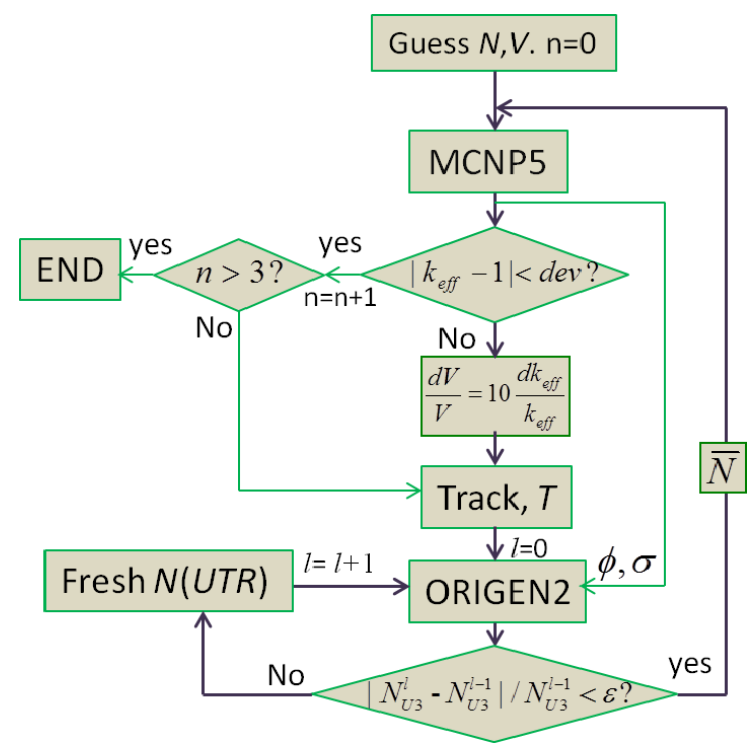

Fig. 3. Flow chart of PBRE with thorium self-sustainability module.

Therefore, two loops are necessary for equilibrium calculation of thorium fuel self-sustainability. The outer loop modifies the feed rate of fresh fuel or in-pile residence time to make $k_{\text {eff }}$ convergent, and the inner loop changes the UTR for fissile self-sustainability. It is notable that the neutron transportation calculation is only performed in the outer loop, which can obviously save computing time.

Equilibrium calculation of thorium fuel self-sustainability has been achieved in PBRE code [30], which is accurately verified by VSOP [31] code with the HTR-10 model. PBRE is an equilibrium state searching code directly skipping the initial state and intermediate state. Method of PBRE is similar to literature $[15,32,33]$. The flow chart of PBRE with thorium self-sustainability is depicted in Figure 3. Guessing an equilibrium concentration of nuclides, MCNP code calculates equilibrium fluxes and onegroup cross-sections of different regions. With the refueling scheme, equilibrium residence time in each region and pebble tracks are determined. Therefore, ORIGEN2 can give average concentrations in different regions and discharge concentrations. By modifying the UTR, fissile self-sustainability can be realized. Iteratively, average concentrations return to MCNP code until the $k_{\text {eff }}$ and concentrations are convergent. If the outer loop is diverging, it means that there does not exist the condition to meet fissile self-sustainability and reactor criticality.

Pebble tracks not only give the calculating order of different regions, but also contain the decay calculation when pebbles are unloaded from each channel. In addition, for mixing flow pattern, a mixing treatment for the same batch from different channels is performed.

\section{Results and discussions}

Discharge burnup for thorium fuel self-sustainability and Temperature Reactivity Coefficient (TRC) of Flibe varied 


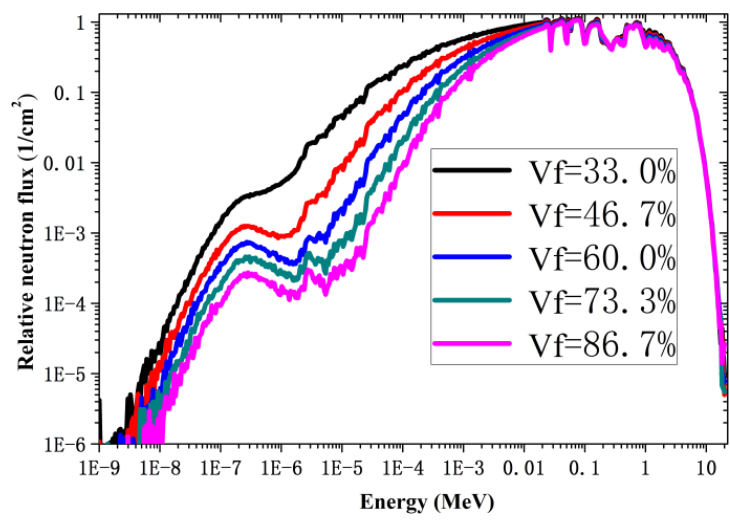

Fig. 4. Neutron spectrum dependent with $V f$ (case 1).

with $V f$ are investigated in this section. For a further analysis of neutronic performance, properties of ${ }^{6} \mathrm{Li},{ }^{233} \mathrm{~Pa}$ effect and radial power distribution are also studied. Finally, preliminary thermal hydraulic is analyzed to give the boundaries of power density and $V f$.

\subsection{Neutron spectrum}

Neutron spectrum provides a vital role for breeding or selfsustainability calculation. In the following analysis, $V f$ is a main parameter to adjust neutron spectrum. As shown in Figure 4, neutron spectrum varies from quasi-fast spectrum to fast spectrum with the increase of $V f$. There are several dips around high energy range, corresponding to the main elastic scattering resonance of ${ }^{7} \mathrm{Li}$ and ${ }^{19} \mathrm{~F}$. In addition, there is a low peak at about $0.2 \mathrm{eV}$ caused by thermal scattering of carbon from $\mathrm{SiC}$ and graphite reflector, but note that the peak is two or three orders of magnitude lower than the fast flux.

\subsection{Discharge burnup for thorium fuel self-sustainability}

In this section, the aim is to find the feasible region of thorium fuel self-sustainability and further to investigate the burnup characteristic of thorium fuel self-sustainability.

Discharge burnup for thorium fuel self-sustainability with different cases is shown in Figure 5. Discharge burnup is a function of $V f$. High $V f$ can linearly improve the discharge burnup. For $V f$ lower than $20 \%$, the discharge burnup is near to zero, which implies that it may not be feasible to breed for thorium fuel in PB-FHRs when $V f$ is below $20 \%$.

The mechanism of discharge burnup for thorium fuel self-sustainability variation with $V_{f}$, can be understood in terms of the one-group cross-section ratios of thoriumuranium and UTR (Fig. 6). The one-group absorption cross-section ratio of thorium to uranium (XS(Tha)/XS (U3a)) reflects the conversion capability of thorium. The one-group fission-absorption ratio of ${ }^{233} \mathrm{U}$ (XS(U3f)/XS (U3a)) reflects ${ }^{233} \mathrm{U}$ fuel burning efficiency. As shown in Figure 6, a hard neutron spectrum provides high XS(Tha)/

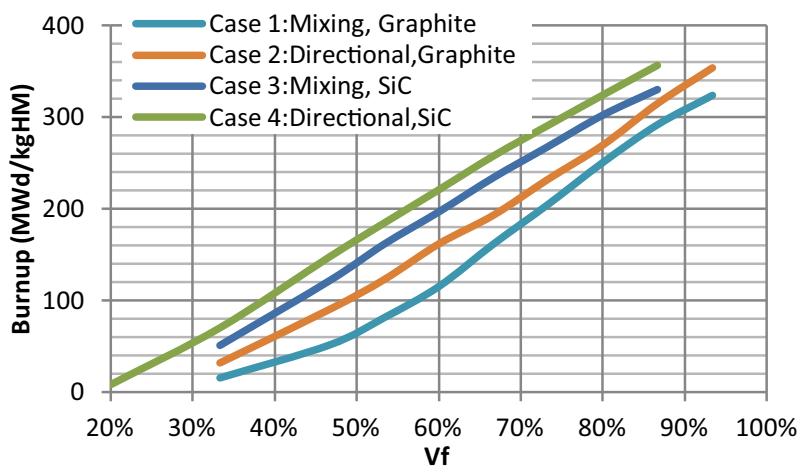

Fig. 5. Discharge burnup for thorium fuel self-sustainability in different cases as a function of $V f$.

$\mathrm{XS}(\mathrm{U} 3 \mathrm{a})$ and high $\mathrm{XS}(\mathrm{U} 3 \mathrm{f}) / \mathrm{XS}(\mathrm{U} 3 \mathrm{a})$, which show high conversion capability and high fuel burning efficiency. In the low $V f$ region, UTR increases mainly due to the increase of XS(Tha)/XS(U3a) to keep reactor criticality, while in high $V f$ region, higher fuel burning efficiency and lower neutron absorption cross-section of fission products will allow lower fresh UTR (Fig. 6). When XS(Tha)/XS(U3a) is higher than UTR, breeding of thorium is feasible and extra ${ }^{233} \mathrm{U}$ will be produced to improve the discharge burnup of thorium fuel. The evolution of ${ }^{233} \mathrm{U}$ in case 4 with $46.7 \% V f$ is shown in Figure 7. Concentration of ${ }^{233} \mathrm{U}$ will

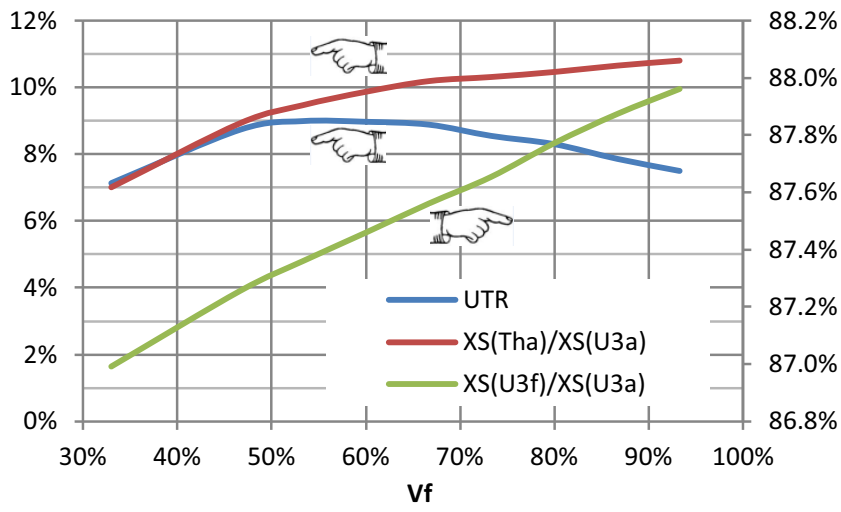

Fig. 6. One-group cross-section ratio and concentration ratio of thoirum-uranium (case 2).

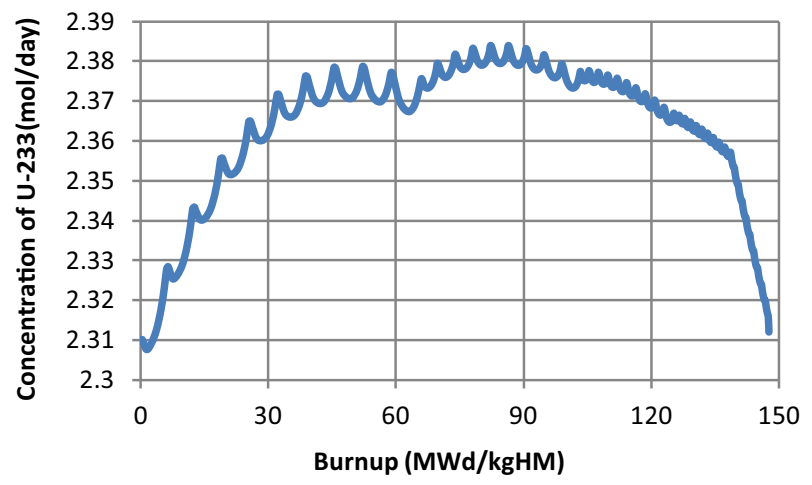

Fig. 7. Evolution of ${ }^{233} \mathrm{U}$ in case 4 with $46.7 \% \mathrm{Vf}$. One wave represents a single passage caused by the delay of ${ }^{233} \mathrm{~Pa}$ decay. 


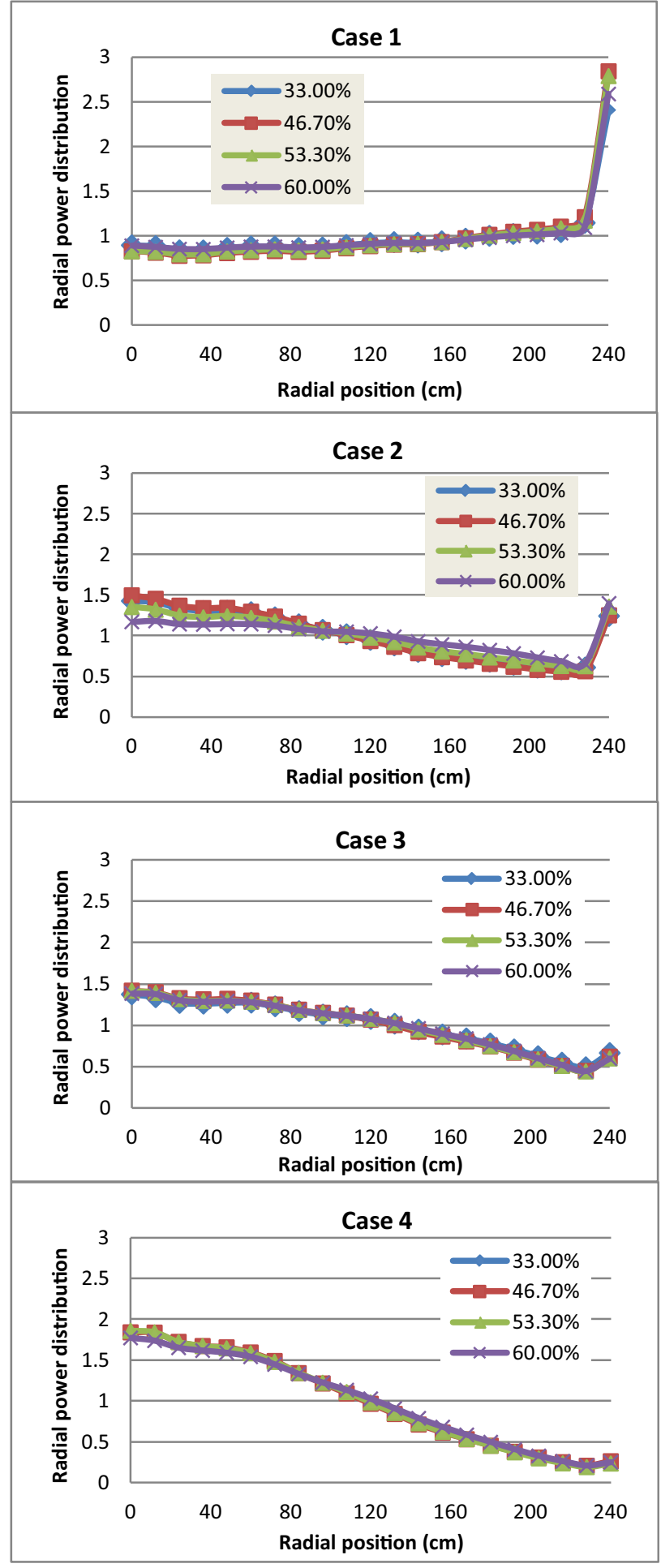

Fig. 8. Radial power distribution with different $V f$ and cases. Radial power distribution is tallied by TMESH card in column grid. In case 1 and case 2, power fraction in the outer channel increases because of strong slowing down effect by graphite reflector.

increase at low burnup and decrease to the initial concentration at the high burnup.

As shown in Figure 5, a directional flow pattern can provide higher discharge burnup than a mixing flow pattern, and a $\mathrm{SiC}$ reflector can provide higher discharge burnup than a graphite reflector. Reflector material has a more significant influence than flow pattern on discharge burnup in comparing case 2 and case 3 . The neutron leakage rate and slowing down effect by reflector are the main contributions to differences among the four cases. In directional flow pattern, radial power fraction concentrates in the inner channel (Fig. 8) because of more ${ }^{233} \mathrm{U}$, low fission products and consequent high flux in inner channel, which will decrease neutron leakage (Fig. 9) and lead to weak slowing down effect by reflector, and vice versa in mixing flow pattern. Additionally, power fraction in outer channel will be enhanced by graphite reflector due to the large fission cross-section caused by strong slowing down effect, which will further increase the neutron leakage (Fig. 9).

For $50 \% \mathrm{Vf}$ dispersion fuel, a discharge burnup of $63 \mathrm{MWd} / \mathrm{kgHM}, 103 \mathrm{MWd} / \mathrm{kgHM}, 140 \mathrm{MWd} / \mathrm{kgHM}$ and $165 \mathrm{MWd} / \mathrm{kgHM}$ can be achieved in case 1 to case 4 , respectively. From a view of same discharge burnup, case 4 could provide smallest $V f$ to reduce the manufacturing difficulty of fuel system. However, radial power peak factor case 4 is about 1.8. Case 3 is the best tradeoff between discharge burnup and radial power peak factor (about 1.4), and mixing flow pattern is the simplest refueling scheme.

\subsection{Thickness of reflector}

To decrease the neutron leakage, thickness of reflector is analyzed. As shown in Figure 10, the thickness of graphite reflector has an apparent positive effect on the k-eff due to the strong slowing down power, which will lead to a lower breeding capacity or discharge burnup. However, neutron leakage rate almost does not vary with the thickness of graphite reflector (Fig. 11), which may be caused by offset between the enhanced power fraction in the outer channel and the enhanced reflectivity. As analyzed above, graphite reflector seems not suitable in this reactor. From Figures 10 and $11,50 \mathrm{~cm}$ thickness seems enough for $\mathrm{SiC}$ reflector to prevent neutron from escaping.

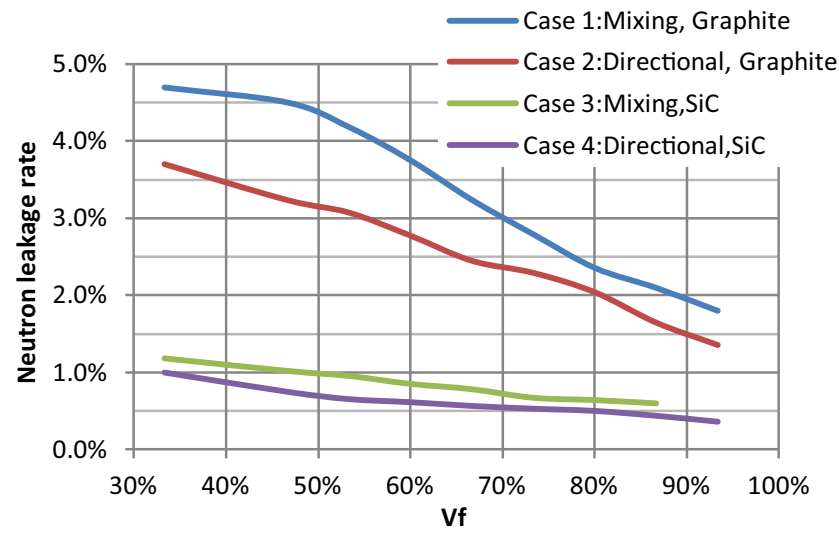

Fig. 9. Neutron leakage rate as a function of $V f$ with four cases. Neutron leakage rate is the escaped fraction outside the reflectors. Reflector with graphite material leads to more leakage than with $\mathrm{SiC}$ material. 


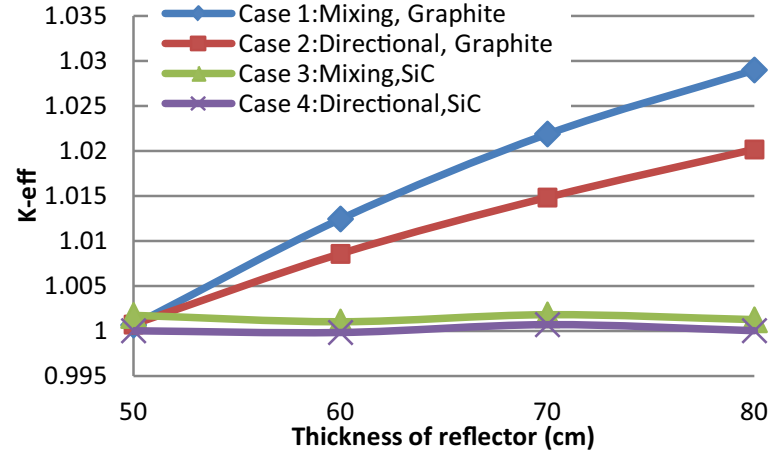

Fig. 10. k-eff with equilibrium concentrations as a function of reflector thickness and cases.

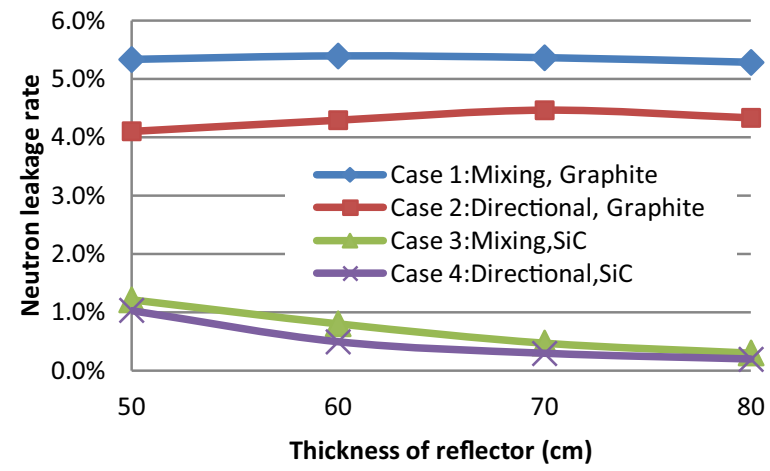

Fig. 11. Neutron leakage rate as a function of reflector thickness and cases. Neutron leakage rate is the sum of escaped fraction outside the reflector and neutron absorption rate of reflectors.

\subsection{Flibe temperature reactivity coefficient}

A negative Flibe TRC is necessary for PB-FHR nuclear safety. The calculated Flibe TRC is shown in Figure 12. As the increase of $V_{f}$, Flibe TRC increases. A positive Flibe TRC will happen when $V f$ is beyond $62 \%$, which shows the margin of inherent safety.

Comparing different cases, case 1 and case 2 show the more negative Flibe TRC than case 3 and case 4 , which could be explained by softer spectrum in case 1 and case 2 .

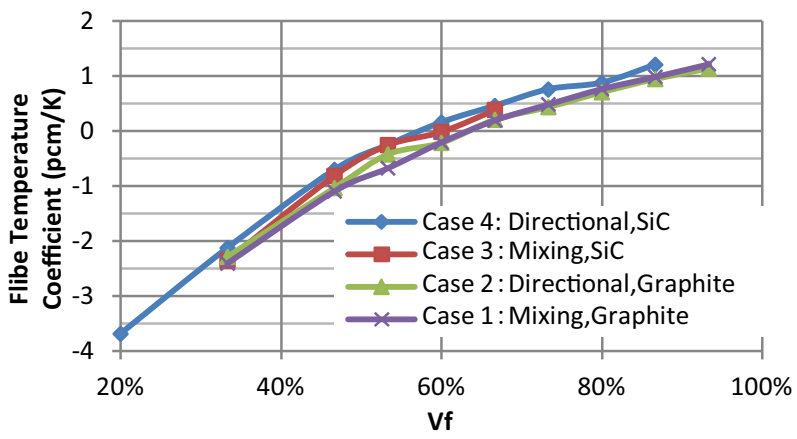

Fig. 12. Flibe salt temperature reactivity coefficient in different cases. Temperature changes from $920 \mathrm{~K}$ to $1050 \mathrm{~K}$, and density of Flibe changes from 1.96 to $1.91 \mathrm{~g} / \mathrm{cm}^{3}$.

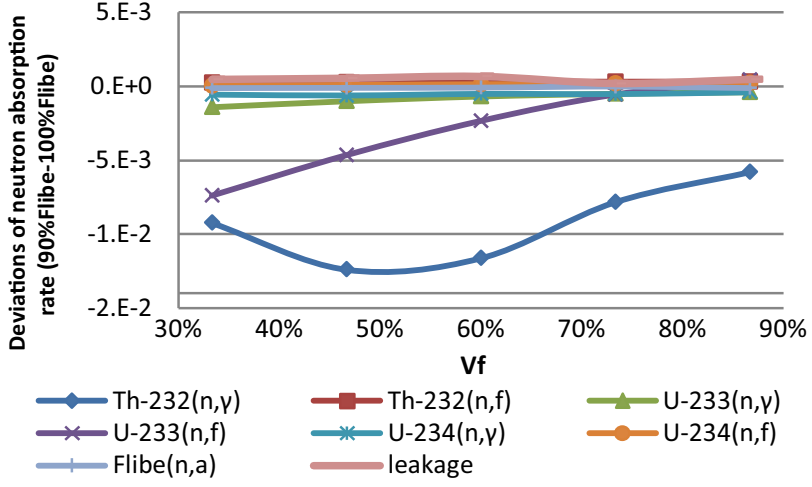

Fig. 13. Deviations of neutron absorption rate of main nuclides as a function of $V f$ (case 4$)$.

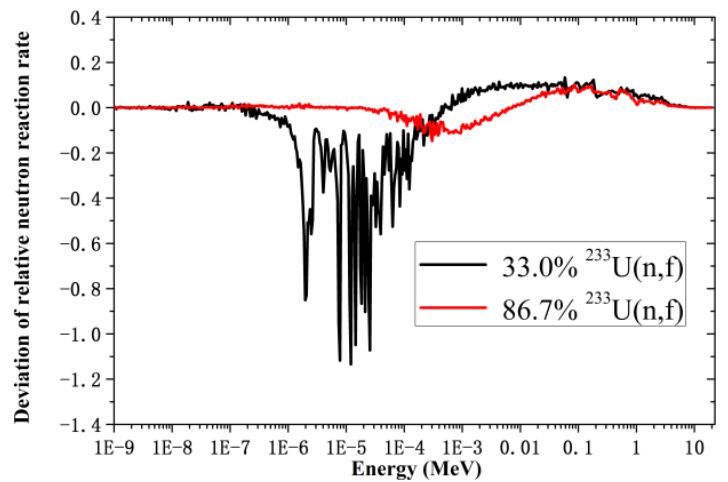

Fig. 14. Deviations of ${ }^{233} \mathrm{U}(\mathrm{n}, \mathrm{f})$ reaction (90\%Flibe-100\%Flibe) as a function of neutron energy.

The mechanism of Flibe TRC is analyzed in models with $10 \%$ voided Flibe. The deviations of neutron absorption rate of main nuclides are shown in Figure 13. The ${ }^{232} \mathrm{Th}$ $(\mathrm{n}, \gamma)$ reaction and ${ }^{233} \mathrm{U}(\mathrm{n}, \mathrm{f})$ reaction make great contributions to Flibe TRC. ${ }^{232} \mathrm{Th}(\mathrm{n}, \gamma)$ makes Flibe TRC more positive, while ${ }^{233} \mathrm{U}(\mathrm{n}, \mathrm{f})$ makes Flibe TRC more negative. With the increase of $V_{f}$, the deviation of ${ }^{233} \mathrm{U}(\mathrm{n}, \mathrm{f})$ reaction approaches zero, as can be explained with reference to Figure 14. In $33.0 \% \quad V_{f}$, the ${ }^{233} \mathrm{U}(\mathrm{n}, \mathrm{f})$ reaction in the resonance region has obvious shortfalls when slowing down by Flibe, while in $86.7 \% V_{f}$, the deviation in resonance region vanishes. The same situation happens with ${ }^{232} \mathrm{Th}$ $(\mathrm{n}, \gamma)$. This indicates that some level of slowing down is required to keep a negative Flibe TRC and this could not be achieved for solid thorium fuel in a fast neutron spectrum.

Figure 13 also shows the contribution of neutron leakage, Flibe absorption rate and other reaction rates to Flibe TRC. Neutron leakage makes the Flibe TRC a little negative, while Flibe absorption rate and other reaction rates make the Flibe TRC a little positive.

\subsection{Equilibrium concentration of $\mathrm{Li}-6$ and production rate of $\mathrm{H}-3$}

The absorption rates of each nuclide in Flibe are shown in Figure 15 . The ${ }^{9} \mathrm{Be}(\mathrm{n}, 2 \mathrm{n})$ reaction rate is predominant, 


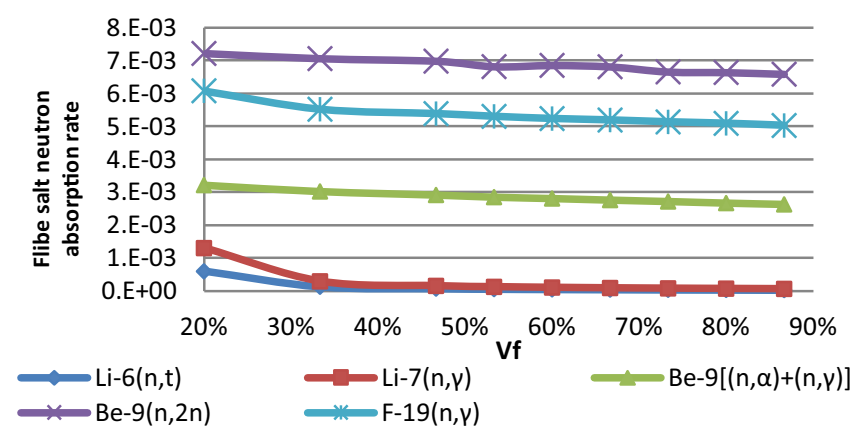

Fig. 15. Absorption rate of each nuclide in Flibe as a function of Vf (case 4).

which could help reduce contribution to positive Flibe TRC. The ${ }^{19} \mathrm{~F}(\mathrm{n}, \gamma)$ reaction is apparent for several capture resonance peaks in fast spectrum. Notably, different from thermal spectrum, ${ }^{6} \mathrm{Li}$ and ${ }^{7} \mathrm{Li}$ show the low neutron absorption characteristics in a quasi-fast spectrum. The discharge burnup and Flibe TRC variations with concentration of ${ }^{6} \mathrm{Li}$ are shown in Figure 16. With the increase of ${ }^{6} \mathrm{Li}$, discharge burnup decreases, while Flibe TRC does not change until beyond $3000 \mathrm{ppm}$. But it notes that discharge burnup only has a $6 \mathrm{MWd} / \mathrm{kgHM}$ drop when ${ }^{6} \mathrm{Li}$ increases from $22 \mathrm{ppm}$ to $500 \mathrm{ppm}$, which shows that 99.95 at. $\%{ }^{7} \mathrm{Li}$ at least is compatible for sustainability of thorium-uranium in PB-FHR. This indicates that the cost of Flibe in quasifast reactor can be sharply reduced by lower enrichment of ${ }^{7} \mathrm{Li}$.

In fact, the equilibrium concentration of ${ }^{6} \mathrm{Li}$ in a quasifast spectrum is very much larger than in a thermal spectrum. This can be calculated by equation (9), by assuming that the concentration of ${ }^{9} \mathrm{Be}$ in the core is constant.

$$
N_{L i-6}=\frac{(n, \alpha) \text { reaction rate of } \mathrm{Be}-9}{\text { absorption rate of } \mathrm{Li}-6(22 \mathrm{ppm})} \cdot 22 \mathrm{ppm} \text {. }
$$

As shown in Figure 17, the equilibrium of ${ }^{6} \mathrm{Li}$ increases as the increase of $V f$ due to the faster decline of one-group

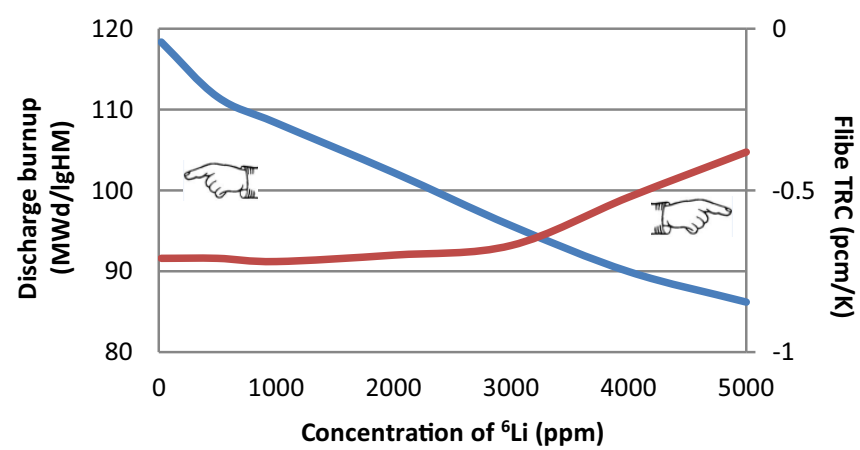

Fig. 16. Discharge burnup and Flibe temperature reactivity coefficient as functions of ${ }^{6} \mathrm{Li}$ concentration $\left(30 \mathrm{MW} / \mathrm{m}^{3}\right.$ power density with $46.7 \%$ Vf in case 4 ).

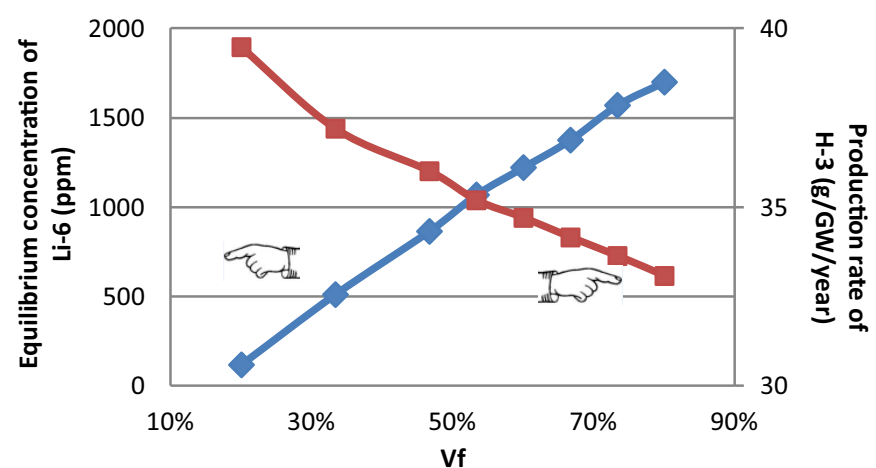

Fig. 17. Equilibrium concentration of Li- 6 and production rate of $\mathrm{H}-3$ as functions of $V f$ in case 4 .

absorption cross-section of ${ }^{6} \mathrm{Li}$ than that of ${ }^{9} \mathrm{Be} .500 \mathrm{ppm}$ of ${ }^{6} \mathrm{Li}$ can be achieved for $33 \% V_{f}$, which implies that enriching the ${ }^{7} \mathrm{Li}$ to more than 99.95 at.\% level for improving the discharge burnup is unnecessary.

The product rate of ${ }^{3} \mathrm{H}$ in equilibrium state can be estimated by equation (10). Number of ${ }^{233} \mathrm{U}$ fission neutron is assumed to be 2.5 , fission energy of ${ }^{233} \mathrm{U}$ is assumed to be $200 \mathrm{MeV}$. The product rate of ${ }^{3} \mathrm{H}$ is equal to the $(\mathrm{n}, \alpha)$ reaction rate of ${ }^{9} \mathrm{Be}$. Figure 17 shows that the product rate of ${ }^{3} \mathrm{H}$ in equilibrium state decreases as the increase of $V_{f}$, which is in keeping with the $(n, \alpha)$ reaction rate of ${ }^{9}$ Be shown in Figure 15. Since the $(n, \alpha)$ reaction rate of ${ }^{9} \mathrm{Be}$ in quasifast spectrum is low, the product rate of ${ }^{3} \mathrm{H}$ is only about $30-40 \mathrm{~g} / \mathrm{GW} /$ year, which is not proportional to the concentration of ${ }^{6} \mathrm{Li}$.

$$
P_{\mathrm{H}-3}=\frac{(n, \alpha) \text { reaction rate of } \mathrm{Be}-9}{200 \mathrm{MeV}} \cdot 2.5 .
$$

\subsection{Effect of ${ }^{233} \mathrm{~Pa}$}

In the conversion process of thorium, some of the ${ }^{233} \mathrm{U}$ will be lost by the irradiation of ${ }^{233} \mathrm{~Pa}$. This effect can be enhanced by a high neutron flux. As shown in Figure 18, discharge burnup has a $30 \mathrm{MWd} / \mathrm{kgHM}$ drop when power

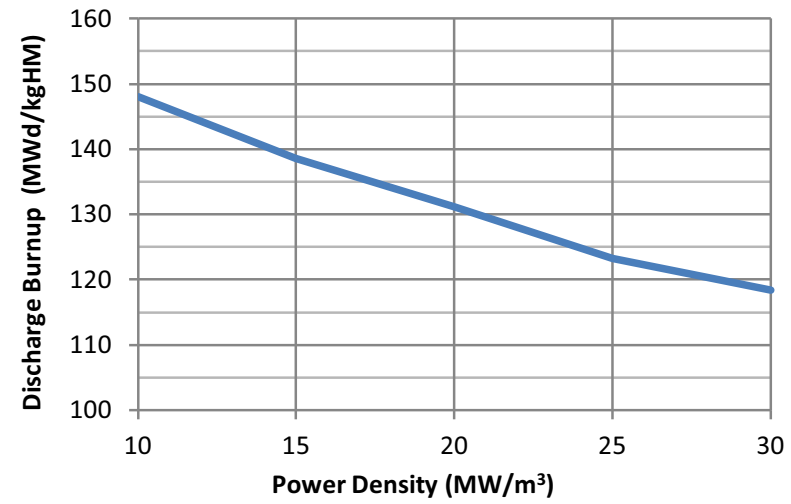

Fig. 18. Discharge burnup as a function of power density $(46.7 \%$ Vf in case 4). 


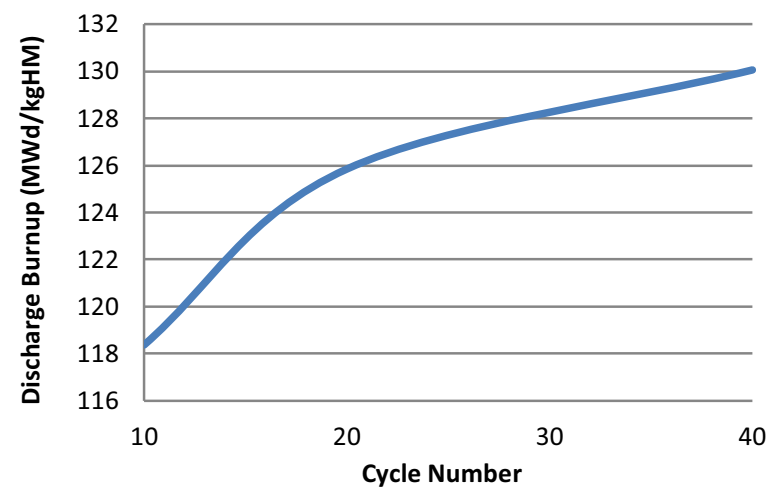

Fig. 19. Discharge burnup as a function of pebble cycle number in each channel. $30 \mathrm{MW} / \mathrm{m}^{3}$ power densities with $46.7 \% \mathrm{Vf}$ in case 4 .

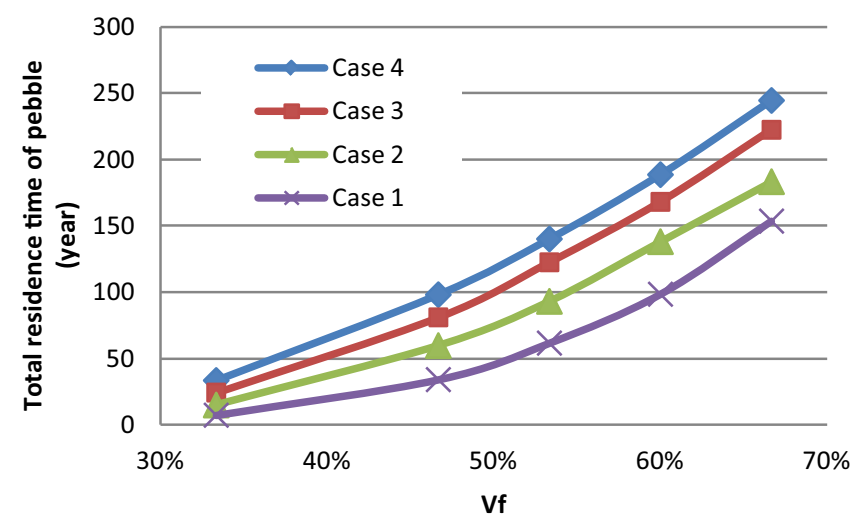

Fig. 20. Total residence time of pebble as a function of $V f$ and cases $\left(10 \mathrm{MW} / \mathrm{m}^{3}\right.$ power density).

density increases from 10 to $30 \mathrm{MW} / \mathrm{m}^{3}$. In PB-FHRs, ${ }^{233} \mathrm{~Pa}$ has opportunity to decay away by periodically removing pebbles from the core. Figure 19 shows that the discharge burnup in high power density condition can be improved by increasing the number of times each pebble is cycled through each channel. However, this effect becomes weak when number of cycles in each channel extends beyond 20 .

Because of the low power density and high fuel loading, the residence time of each pebble in this reactor is very long (Fig. 20). It is necessary to reduce the residence time by increasing the power density and decreasing the fuel loading or $V f$. For $46.7 \% V f$ in case 4, if the core power density is $40 \mathrm{MW} / \mathrm{m}^{3}$, the discharge burnup may drop from 148 to about $100 \mathrm{MWd} / \mathrm{kgHM}$ for the effect of ${ }^{233} \mathrm{~Pa}$, the residence time of a pebble will be 17 years.

\subsection{Thermal hydraulic analysis}

In this section, $V f$ and power density will further be limited by thermal hydraulics considerations. For dispersion fuel system, a one-dimensional sphere geometry with equivalent thermal conductivity is used. By reference to HTGRs [34], the limit temperature of fuel in normal conditions is assumed to be $1250{ }^{\circ} \mathrm{C}$, and the limit temperature of fuel in accident conditions is supposed to be $1600{ }^{\circ} \mathrm{C}$.

The maximum kernel temperature can be deduced from the maximum temperature of mixed fuel region:

$$
\begin{aligned}
T_{k}= & T_{f}+\frac{P \cdot f \cdot r_{1}^{2}}{6 k_{f u e l}(1-\varepsilon) \cdot V_{f}}+\frac{P \cdot f \cdot r_{1}^{3}}{3 k_{b u f f e r}(1-\varepsilon) \cdot V_{f}\left(1 / r_{1}-1 / r_{2}\right)} \\
& +\frac{P \cdot f \cdot r_{1}^{3}}{3 k_{S i C}(1-\varepsilon) \cdot V_{f}\left(1 / r_{2}-1 / r_{3}\right)} .
\end{aligned}
$$

$T_{f}$ is maximum temperature of mixed fuel region, $P$ is the average power density, $f$ is the total power peak factor (assumed as $1.4 \times 1.4 \approx 2$ in the following calculation), $\varepsilon$ is porosity of pebble bed, $k_{\text {fuel }}$ is thermal conductivity of thorium-uranium fuel, $k_{\text {buffer }}$ is thermal conductivity of buffer, $k_{S i C}$ is thermal conductivity of $\mathrm{SiC}$ cladding, $r_{1}$ is the radius of fuel kernel, $r_{2}$ is the outer radius of buffer and $r_{3}$ is the outer radius of $\mathrm{SiC}$ cladding.

The maximum temperature of mixed fuel region can be obtained by:

$$
T_{f}=T_{s}+\frac{P \cdot f \cdot R^{2}}{6 k(1-\varepsilon)} .
$$

$T_{s}$ is the surface temperature of pebble; $R$ is the radius of pebble; $k$ is equivalent thermal conductivity, in this paper, it is the volume average thermal conductivity, which will vary with $V f$.

The surface temperature of pebble can be obtained by heat convection equation:

$$
T_{s}=T_{c}+\frac{4 P \cdot f \cdot R^{2}}{3 k_{c} N u(1-\varepsilon)}, N u=2+1.1 \operatorname{Re}^{0.6} \operatorname{Pr}^{1 / 3} .
$$

$T_{c}$ is the average temperature of Flibe, $k_{c}$ is the thermal conductivity of Flibe, $\mathrm{Nu}$ is nusselt number cited from Wakao [35], Re is Reynolds number, and $\mathrm{Pr}$ is Prandtl number.

$$
R e=\frac{\rho U \cdot 2 R}{\mu(1-\varepsilon)}, \operatorname{Pr}=\mu C_{p} / k_{c} .
$$

$\rho$ is the density of Flibe, $\mu$ is dynamic viscosity, $C_{p}$ is heat capacity, $U$ is superficial velocity of Flibe. $U$ can be calculated by:

$$
U=\frac{P \cdot h}{C_{p \cdot \rho \cdot\left(T_{\text {outlet }}-T_{\text {inlet }}\right)},}
$$

$h$ is the height of core, $T_{\text {outlet }}$ is outlet temperature of Flibe, and $T_{\text {inlet }}$ is inlet temperature of Flibe.

The physical property parameters are listed in Table 4, the thermal conductivity of $\mathrm{SiC}$ is very high even after a long period of irradiation time, the thermal conductivity of $\mathrm{Th}_{2} \mathrm{CO}_{3} / \mathrm{U}_{2} \mathrm{CO}_{3}$ is referred from that of $\mathrm{ThO}_{2}$, which shows a little higher thermal conductivity than $\mathrm{UO}_{2}$. 
Table 4. Constants for thermal hydraulic calculations.

\begin{tabular}{ll}
\hline Parameter & Value \\
\hline$\varepsilon$ & 0.4 \\
$k_{c}$ & $1 \mathrm{~W} / \mathrm{m}^{\circ} \mathrm{C}$ \\
$k_{S i C}$ & $30 \mathrm{~W} / \mathrm{m}^{\circ} \mathrm{C}$ \\
$k_{\text {fuel }}$ & $4 \mathrm{~W} / \mathrm{m}^{\circ} \mathrm{C}$ \\
$k_{\text {buffer }}$ & $9 \mathrm{~W} / \mathrm{m}^{\circ} \mathrm{C}$ \\
$\rho$ & $1.96 \times 10^{3} \mathrm{~kg} / \mathrm{m}^{3}$ \\
$\mu$ & $8.153 \times 10^{-3} \mathrm{~Pa} \cdot \mathrm{s}$ \\
$C_{p}$ & $2.38 \times 10^{3} \mathrm{~J} / \mathrm{kg} /{ }^{\circ} \mathrm{C}$ \\
$h$ & $5 \mathrm{~m}$ \\
$T_{\text {inlet }}$ & $600{ }^{\circ} \mathrm{C}$ \\
$T_{\text {outlet }}$ & $700^{\circ} \mathrm{C}$ \\
$T_{c}$ & $650{ }^{\circ} \mathrm{C}$ \\
$r_{1}$ & $700 \mu \mathrm{m}$ \\
$r_{2}$ & $758 \mu \mathrm{m}$ \\
$r_{3}$ & $819 \mu \mathrm{m}$ \\
\hline
\end{tabular}

The results are shown in Table 5. As the increase of $V_{f}$, the equivalent thermal conductivity decreases, as a result, the maximum temperature of fuel increases. However, even in $60 \% V_{f}$, the maximum temperature of fuel is still below $1250{ }^{\circ} \mathrm{C}$ for $6 \mathrm{~cm}$ pebble under $10 \mathrm{MW} / \mathrm{m}^{3}$ power density. On the other hand, the allowable power density for $6 \mathrm{~cm}$ pebble will not extend beyond $21 \mathrm{MW} / \mathrm{m}^{3}$ if the maximum temperature of fuel is below $1250^{\circ} \mathrm{C}$. Reducing the diameter of pebble is an effective means of improving the power density, as shown in Table $5,60 \mathrm{MW} / \mathrm{m}^{3}$ power density is allowable in $40 \% \mathrm{Vf}$ for $3 \mathrm{~cm}$ pebble.

As analyzed above, thermal conductivity is sensitive to the maximum temperature of the fuel. ThC may be a good candidate ceramic fuel due to the high density and high thermal conductivity.

Loss of Forced Cooling (LOFC) and Anticipated Transient Without Scram (ATWS) are the most important accidents for PB-FHRs. The decay heat removal system with Pool Reactor Auxiliary Cooling (PRAC) heat exchangers (PHX) modules in the PB-AHTR could be applied to this work. In an LOFC accident, even under $40 \mathrm{MW} / \mathrm{m}^{3}$ power density, the outlet temperature of Flibe will not rise by as much as $50^{\circ} \mathrm{C}$, and the temperature of fuel will quickly drop to the level of Flibe [36]. In an ATWS accident with a $1000 \mathrm{pcm}$ reactivity insertion, the temperature of the fuel will not rise by as much as $200^{\circ} \mathrm{C}$ to $1450{ }^{\circ} \mathrm{C}$, which is still lower than $1600{ }^{\circ} \mathrm{C}(-5 \mathrm{pcm} / \mathrm{K}$ of fuel TRC is calculated in $46.7 \% V_{f}$, case 4 ). In addition, the negative Flibe TRC is more effective to decrease the outlet temperature than a more negative fuel TRC, and the outlet temperature in this case will not rise by $200^{\circ} \mathrm{C}$ [36].

\section{Conclusions}

This work investigated the sustainability of thorium fuel in PB-FHR. Dispersion fuel with $\mathrm{SiC}$ cladding and $\mathrm{SiC}$ matrix was used to increase the fuel loading. A novel equilibrium calculation method of thorium fuel self-sustainability was developed to analyze discharge burnup. The mechanism of breeding and the characteristic of Flibe salt temperature reactivity coefficient are both performed.

Some preliminary findings are as follows:

- more than 20 vol\% fuel loading in fuel system is necessary to keep thorium fuel sustainable, and less than $62 \mathrm{vol} \%$ fuel loading is required for negative Flibe TRC. The allowed maximal discharge burnup for thorium fuel selfsustainability and negative Flibe TRC is about $200 \mathrm{MWd} / \mathrm{kgHM}$;

- case 4 with directional flow pattern and $\mathrm{SiC}$ reflector displays superior burnup characteristics due to having the hardest neutron spectrum and lowest neutron leakage. While case 3 with mixing flow pattern and $\mathrm{SiC}$ reflector shows the best tradeoff between discharge burnup and radial power peak factor. For $50 \% \mathrm{Vf}$ dispersion fuel, case 3 could provide $140 \mathrm{MWd} / \mathrm{kgHM}$ burnup and about 1.4 radial power peaking factor;

- the ${ }^{232} \operatorname{Th}(\mathrm{n}, \gamma)$ reaction and ${ }^{233} \mathrm{U}(\mathrm{n}, \mathrm{f})$ reaction are main contributions to Flibe TRC. It indicates that some level of slowing down is required to keep a negative void

Table 5. Temperature distribution in pebble.

\begin{tabular}{llllll}
\hline$V_{f}$ & $20 \%$ & $30 \%$ & $40 \%$ & $50 \%$ & $60 \%$ \\
\hline Equivalent thermal conductivity $(\mathrm{J} / \mathrm{cm} / \mathrm{K})$ & 0.24 & 0.21 & 0.18 & 0.15 & 0.12 \\
\hline $6 \mathrm{~cm}$ & & & & & \\
$T_{s}-T_{c}\left({ }^{\circ} \mathrm{C}\right)$ & 80 & 80 & 80 & 80 & 80 \\
$T_{f}-T_{s}\left({ }^{\circ} \mathrm{C}\right)$ & 208 & 237 & 277 & 332 & 415 \\
$T_{k}-T_{f}\left({ }^{\circ} \mathrm{C}\right)$ & 3.7 & 2.5 & 1.8 & 1.5 & 1.2 \\
Max. $T_{k}\left({ }^{\circ} \mathrm{C}\right)$ & 941 & 970 & 1009 & 1063 & 1146 \\
Allowable Avr. P.D. $\left(\mathrm{MW} / \mathrm{m}^{3}\right)$ & 21 & 19 & 17 & 15 & 12 \\
$3 \mathrm{~cm}$ & & & & 764 & 784 \\
Max. $T_{k}\left({ }^{\circ} \mathrm{C}\right)$ & 733 & 740 & 750 & 60 & 53 \\
Allowable Avr. P.D. $\left(\mathrm{MW} / \mathrm{m}^{3}\right)$ & 72 & 67 & & & 45 \\
\hline
\end{tabular}


reactivity coefficient, which provides a new insight for coolant in quasi-fast reactor. Flibe salt shows good neutron properties as coolant of quasi-fast reactor. The equilibrium concentration of ${ }^{6} \mathrm{Li}$ in fast spectrum is around $1000 \mathrm{ppm}$, which decreases the cost of enrichment, and the neutron absorption of ${ }^{6} \mathrm{Li}$ is still low. $99.95 \%{ }^{7} \mathrm{Li}$ is compatible for sustainability of thoriumuranium in PB-FHR. In addition, the production rate of ${ }^{3} \mathrm{H}$ in quasi-fast spectrum is about $30-40 \mathrm{~g} / \mathrm{GW} /$ year, usually lower than in thermal spectrum;

- effect of ${ }^{233} \mathrm{~Pa}$ is significant in the high power density condition. A $30 \mathrm{MWd} / \mathrm{kgHM}$ drop in discharge burnup is obtained when power density increases from 10 to $30 \mathrm{MW} / \mathrm{m}^{3}$. Increasing the number of time each thorium pebble is cycled through each channel can increase discharge burnup. The greatest challenge of this reactor is the very long irradiation time of the pebble fuel. Increasing power density can apparently decrease the irradiation time, but discharge burnup will also obviously decrease, and as a result, the reactor may not be competitive;

- thermal hydraulic calculations show good safety margin. $20 \mathrm{MW} / \mathrm{m}^{3}$ is allowable for $6 \mathrm{~cm}$ pebble, and $60 \mathrm{MW} / \mathrm{m}^{3}$ is allowable for $3 \mathrm{~cm}$ pebble. $V f$ affects the thermal conductivity, and a value lower than $50 \%$ is recommended.

In further analysis, we will focus on the high power density case, investigate how to reduce the effect of ${ }^{233} \mathrm{~Pa}$, and also perform a detail thermal hydraulic analysis.

This paper is supported by the "Strategic Priority Research Program" of the Chinese Academy of Sciences (Grant No. XDA02010200), and Science and Technology Commission of Shanghai Municipality (Grant No. 11JC1414900). Thanks for the suggestions from David W. Dean and reviewers.

\section{Nomenclature}

PB-FHR

$$
V_{f}
$$

UTR $\mathrm{XS}(\mathrm{Tha}) / \mathrm{XS}(\mathrm{U} 3 \mathrm{a})$

$\mathrm{XS}(\mathrm{U} 3 \mathrm{f}) / \mathrm{XS}(\mathrm{U} 3 \mathrm{a})$

TRC

\section{References}

1. IAEA, Role of thorium to supplement fuel cycles of future nuclear energy systems, Nuclear Energy Series No. NF-T-2.4, Vienna, 2012

2. B.A. Lindley et al., Thorium breeder and burner fuel cycles in reduced-moderation LWRs compared to fast reactors, Prog. Nucl. Energy 77, 107 (2014)
3. S. Permana, N. Takaki, H. Sekimoto, Preliminary study on feasibility of large and small water cooled thorium breeder reactor in equilibrium states, Prog. Nucl. Energy 50, 320 (2008)

4. S. Permana, N. Takaki, H. Sekimoto, Breeding capability and void reactivity analysis of heavy-water-cooled thorium reactor, J. Nucl. Sci. Technol. 45, 589 (2008)

5. S. Permana, N. Takaki, H. Sekimoto, Breeding and void reactivity analysis on heavy metal closed-cycle water cooled thorium reactor, Ann. Nucl. Energy 38, 337 (2011)

6. S. Sahin et al., Investigation of CANDU reactors as a thorium burner, Energy Convers. Manag. 47, 1661 (2006)

7. A. Kumar, P.V. Tsvetkov, Optimization of U-Th fuel in heavy water moderated thermal breeder reactors using multivariate regression analysis and genetic algorithms, Ann. Nucl. Energy 85, 885 (2015)

8. Y. Yulianti, Z. Su'ud, N. Takaki, Accident analysis of heavy water cooled thorium breeder reactor, in The 5th Asian physics symposium (APS 2012), (AIP Publishing, 2015), Vol. 1656

9. F. Wols et al., Core design and fuel management studies of a thorium-breeder pebble bed high-temperature reactor, Nucl. Technol. 186, 1 (2014)

10. E.S. Bettis, R.C. Robertson, The design and performance features of a single-fluid molten-salt breeder reactor, Nucl. Appl. Technol. 8, 190 (1970)

11. A. Nuttin et al., Potential of thorium molten salt reactors detailed calculations and concept evolution with a view to large scale energy production, Prog. Nucl. Energy 46, 77 (2005)

12. J. Serp, M. Allibert, O. Benes et al., The molten salt reactor (MSR) in generation IV: overview and perspectives, Prog. Nucl. Energy 77, 308 (2014)

13. C.W. Forsberg, P.F. Peterson, R.A. Kochendarfer, Design options for the advanced high-temperature reactor, in Proceedings of ICAPP '08, Anaheim, USA (2008), Paper 8026

14. F.-P. Fardin, F. Koenig, Preliminary study of the pebble-bed advanced high temperature reactor (University of California, Berkeley, California, 2006)

15. M. Fratoni, Development and applications of methodologies for the neutronic design of the pebble bed advanced high temperature reactor (PB-AHTR) (University of California, Berkeley, California, 2008)

16. R. Hong et al., Reactor safety and mechanical design for the annular pebble-bed advanced high temperature reactor (University of California, Department of Nuclear Engineering, Berkeley, California, 2009)

17. A. Lafuente, M. Piera, Exploring new coolants for nuclear breeder reactors, Ann. Nucl. Energy 37, 835 (2010)

18. M.K. Meyer, R. Fielding, J. Gan, Fuel development for gascooled fast reactors, J. Nucl. Mater. 371, 281 (2007)

19. R. Stainsby et al., Gas cooled fast reactor research in Europe, Nucl. Eng. Des. 241, 3481 (2011)

20. L.L. Snead et al., Handbook of $\mathrm{SiC}$ properties for fuel performance modeling, J. Nucl. Mater. 371, 329 (2007)

21. L.L. Snead, Y. Katoh, S. Connery, Swelling of SiC at intermediate and high irradiation temperatures, J. Nucl. Mater. 367, 677 (2007)

22. Y. Katoh et al., Radiation effects in $\mathrm{SiC}$ for nuclear structural applications, Curr. Opin. Solid State Mater. Sci. 16, 143 (2012)

23. Y. Katoh et al., Stability of SiC and its composites at high neutron fluence, J. Nucl. Mater. 417, 400 (2011) 
24. Y. Katoh et al., Mechanical properties of advanced SiC fiber composites irradiated at very high temperatures, J. Nucl. Mater. 417, 416 (2011)

25. J.A. Jung et al., Feasibility study of fuel cladding performance for application in ultra-long cycle fast reactor, J. Nucl. Mater. 440, 596 (2013)

26. K. Fukuda, K. Iwamoto, Diffusion behavior of fission product in pyrolytic silicon carbide, J. Nucl. Mater. 75, 131 (1978)

27. D.J. Cumberland, R.J. Crawford, The packing of particles, in Handbook of powder technology (Elsevier, Amsterdam, 1987) Vol. 6, p. 45

28. A.T. Cisneros, E. Greenspan, P. Peterson, Use of thorium blankets in a pebble bed advanced high temperature reactor, in Proceedings of the 2010 International Congress on Advances in Nuclear Power Plants-ICAPP'10, (2010)

29. R. Hong et al., Reactor safety and mechanical design for the annular pebble-bed advanced high temperature reactor (University of California, Department of Nuclear Engineering, Berkeley, California, 2009)

30. G. Zhu, Y. Zou, M. Li et al., Development of burnup calculation code for pebble-bed high temperature reactor at equilibrium state, Atomic Energy Sci. Technol. 49, 890 (2015)
31. E. Teuchert, U. Hansen, K.-A. Haas, VSOP-Computer code system for reactor physics and fuel cycle simulation, Kernforschungsanlage Juelich GmbH (Germany, FR), Institut fuer Reaktorentwicklung, 1980

32. H.D. Gougar, M.O. Abderrafi, W.K. Terry, Advanced core design and fuel management for pebble-bed reactors (Idaho National Laboratory, 2004), No. INEEL/EXT-04-02245

33. A.T. Jr., Cisneros, Pebble bed reactors design optimization methods and their application to the Pebble Bed Fluoride Salt Cooled High Temperature Reactor (PB-FHR) (University of California, Berkeley, California, 2013)

34. D. Hanson et al., Development plan for advanced high temperature coated-particle fuels (General Atomics, San Diego, CA, 2004), PC-000513, Rev. 0

35. N. Wakao, T. Funazkri, Effect of fluid dispersion coefficients on particle-to-fluid mass transfer coefficients in packed beds: correlation of Sherwood numbers, Chem. Eng. Sci. 33, 1375 (1978)

36. A. Griveau et al., Transient thermal response of the PB-AHTR to loss of forced cooling, in Global 2007, UC Berkeley and INL, Boise, Idaho, 9th-13th September, 2007 (2007)

Cite this article as: Guifeng Zhu, Yang Zou, Hongjie Xu, Sustainability of thorium-uranium in pebble-bed fluoride salt-cooled high temperature reactor, EPJ Nuclear Sci. Technol. 2, 8 (2016) 